August, however, investigation was given a fresh impetus by the discovery of vestiges of a remarkable character of what at first sight was thought to be a building of considerable size, assigned tentatively to the last decade of the first century A.D., on the evidence of a coin found on the floor of what appeared to be a kitchen. Further excavation showed that this identification of the character of the structure was premature. The new discovery can now be seen to be of far greater importance, and indeed, in certain respects it seems unique. The wall, so far as at present uncovered, a distance of some $230 \mathrm{ft}$., according to a report in The Times of August 10, runs east and west almost in a straight line. The foundations, which remain in situ to a height of several inches, vary in breadth from $2 \mathrm{ft}$. 6 in. to $3 \mathrm{ft}$. At regular intervals of $17 \mathrm{ft}$. on both faces of the wall are small buttresses, $2 \mathrm{ft}$. square in plan. The method of construction is interesting. It points to a severe economy on the part of the builders, no doubt owing to the scarcity of suitable stone in East Anglia. The core of the wall is composed of a coarse gravelly rubble with a frequent mixture of broken amphoræ, mortaria and roof-tiles. Only a few fragments of the stone coping remain. The excavators hesitate to offer any conjecture as to the purpose of the wall; but they are of the opinion that it is probably unique in the British Isles.

\section{Civilian Respirators}

UNDER the title "Civilian Respirators" an article in the August issue of the Industrial Chemist discusses the general requirements of apparatus for the protection of the civilian population in the event of hypothetical hostilities involving the use of lethal gases. It is well known that public opinion is divided on the question whether it is desirable to discuss these matters in the present temper of Europe. Some hold that peace is endangered by even humanitarian preparations in case of war; others consider that it would be folly to ignore the possibilities of a new form of warfare, and that common prudence dictates the examination of all measures necessary to combat it. In any event, if measures are to be taken, it is at least common sense to take the best available; and in this matter of the design of respirators suitable for civilian use, the article to which we refer suggests to potential inventors the following general requirements: (1) A canister should be attached directly to a complete facepiece. (2) The canister should provide a protection of 2 minutes against 1 per cent of phosgene, and 20-30 minutes against $0 \cdot 1$ per cent. The resistance should not exceed 3 in. of water. Protection of 10 minutes against 1 in $5 \times 10^{7}$ of diphenylchlorarsine or diphenylaminechlorarsine should be provided. The canister should be readily replaceable and should last for at least five years. (3) The facepiece, of rubber or leather, should be gastight, in not more than three sizes, and should incorporate eyepieces or a window. It should be simple in design, should interfere as little as possible with ordinary duties, should be suitable for mass production from materials available in Great Britain, and should last for at least five years. (4) The cost should be as low as possible. Let us equally bear in mind that industrial respirators and their possibilities are already familiar in chemical factories, and that any new advances will be of great interest in many peaceable occupations.

\section{Direction Finding and Blind Flying for Civil Aviation}

IT has been announced that the Directorate of Civil Aviation, Air Ministry, and the National Physical Laboratory, are co-operating in the study of problems relative to 'blind' flying as applied to air-line operation. The immediate necessities are three-fold, and the use of wireless transmission appears to offer the most likely means of their solution. They are : (1) The transmission of direction finding information over as long a range as possible, probably by short-wave radio. (2) Devices for warning the pilot of the proximity of obstructions such as high masts, or even other aircraft, in conditions of poor visibility. (3) The accurate guiding in and landing of aircraft when an aerodrome is obscured by fog, or in any similar conditions of reduced visibility. The Air Ministry is using a Vickers "Viastra", until recently the property of the Prince of Wales; it will be fitted with the necessary apparatus as soon as preliminary experiments have indicated the most promising type, and will be flown by Imperial Airways pilots. The aerodromes from which they will operate will probably be Croydon, Gatwick, and Gravesend. Imperial Airways will also be invited to send out signals at pre-arranged times, to the pilots of their normal machines, when over Africa and on the way to India and Australia, from which the reliability of different systems can be judged. A type of 'approach' beacon for blind landing, giving out a short aural note over a range of 20-25 miles, has already been ordered for experiment. If this is successful, the problem will then be to develop the use of a long-range direction finding system for use in conjunction with the short-range system, but without interfering with it.

\section{Television in Great Britain Next Year}

The Postmaster-General has now authorised the B.B.C. to make arrangements with the Baird Television Co., Ltd., and the Marconi-E.M.I. Co., Ltd., for the provision of complete transmitting equipment for the operation of their respective systems at the Alexandra Palace, where constructional work has already begun. It is hoped that transmissions will start in the early part of next year, and will be followed as soon as practicable by a regular public service. As ultra-short waves will be transmitted, it will be possible to broadcast scenes in much greater detail than can be done to-day. Doubtless before very long many listening-in sets will be furnished with a television screen. In Germany, television is being pushed forward for political reasons; but in the United States although experimental television is an accomplished fact the business and advertising aspects of the new industry have to be carefully considered. In Great Britain luckily advertisement does not need to be considered, and the Government 